\title{
Algumas considerações sobre o papel da legislação na promoção de projetos de acessibilidade verdadeiramente inclusivos: o caso das pontes de Veneza
}

\author{
Some considerations on the role of legislation in promoting real \\ inclusive accessibility projects: the case of Venice"s bridges
}

WALESKA A. CARVALHO

Doutoranda, Universidade de Lisboa - FAUL, waleska.c@gmail.com

JOSÉ CLEWTON DO NASCIMENTO

Prof. Doutor, UFRN - Departamento de Arquitetura, jotaclewton@gmail.com

JOSÉ RÓGERES MAGALHÃES COSTA

Arquiteto, Tribunal de Justiça do Estado do Ceará, rogerescosta@hotmail.com

\section{RESUMO}

Este texto busca trazer à tona elementos que contribuam para pensar a legislação como elemento importante para incentivar e consolidar uma cultura projetual inclusiva. A experiência de adequação das pontes de Veneza a melhores condições de acessibilidade serve de mote para abordar como essa práxis vem sendo atualizada em realidades diferentes da nossa e como alguns parâmetros técnicos presentes nas normas de acessibilidade podem interferir no desenrolar desse processo. Caracterizada por uma morfologia urbana particularmente desafiadora, a cidade de Veneza tem sido palco, durante as últimas quatro décadas, de experiências que buscam tornar o espaço público acessível a todos. Os obstáculos e as soluções encontradas nesse percurso podem servir de auxílio para discutirmos a partir de nossas próprias coordenadas o caminho que estamos a seguir.

PALAVRAS-CHAVE: Acessibilidade, normas técnicas, pontes de Veneza, Universal Design.

\section{ABSTRACT}

This paper highlights major elements which help us in identifying legislation as key factor to promote and consolidate an inclusive design culture. The experience of adapting Venice"s bridges to accessibility requirements allow us to better understand how this practice has been adjusted in different realities and how some accessibility standards" parameters can interfere in the development of this process. Due to a challenging urban morphology, the city of Venice has been on the stage, for the last four decades, of experiences that seek to make the public space accessible to all. The obstacles and solutions found in this course might help identifying the path from our own starting points.

KEYWORDS: Accessibility, technical standards, Venice"s bridges, Universal Design. 


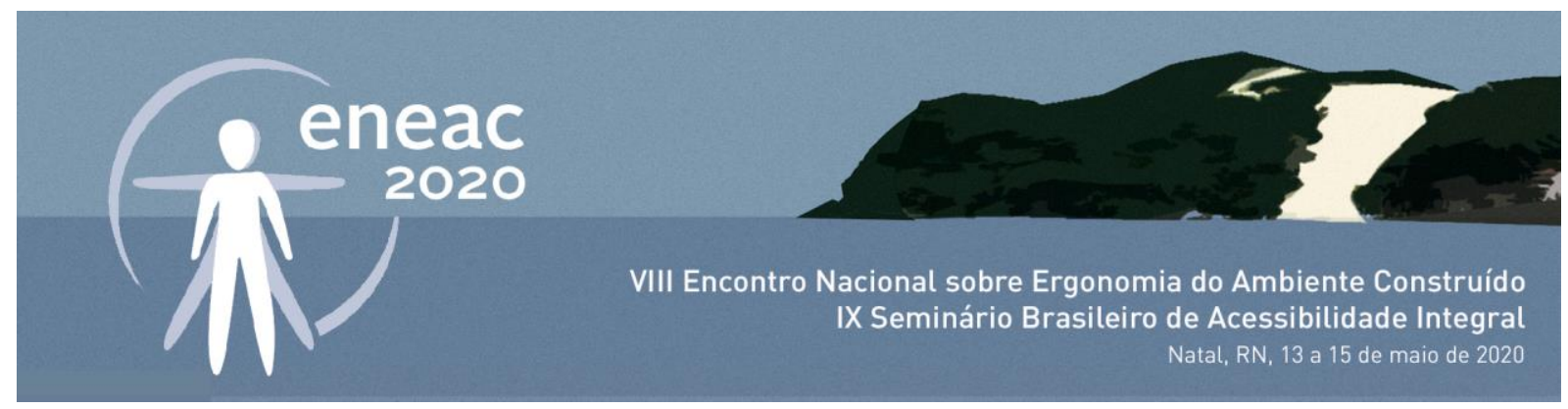

\section{INTRODUÇÃO}

No campo da arquitetura, durante muito tempo, o termo acessibilidade permaneceu quase exclusivamente vinculado à ideia de eliminação das barreiras que se constituíam como obstáculos materiais que impediam uma determinada "categoria de pessoas" de moverem-se com facilidade na cidade e nos edifícios. As denominações "deficiente", "portador de deficiência" etc., utilizadas durante algum tempo para nomear esse grupo de pessoas, ilustra não apenas um modo de identificar um certo grupo, mas exprime também as motivações sociais e culturais que constituíam o pano de fundo referencial para o problema.

Em 2006, por ocasião da Convenção realizada pela Organização das Nações Unidas, a definição do público-alvo das ações de inclusão recomendadas no evento converge para a adoção da expressão "pessoa com deficiência", que coloca a qualidade "deficiente" como dimensão acessória e de relação funcional a respeito da condição mais fundamental do indivíduo ou da pessoa.

As mudanças no léxico utilizado nas discussões sobre o tema da acessibilidade têm, entretanto, uma importância que vai muito além do interesse sociológico a respeito de como se desenvolveu e como foi ampliada a compreensão do problema mais geral da diversidade na sociedade contemporânea. A mudança das palavras reflete as transformações na abordagem do problema, o que nos remete necessariamente a transformações na práxis do projeto arquitetônico.

Este artigo pretende tratar, por meio de alguns exemplos, como essa práxis vem sendo atualizada em função das abordagens atuais do tema "inclusão" e como alguns parâmetros técnicos presentes nas normas de acessibilidade podem interferir no desenrolar desse processo.

\section{0 "DESIGN FOR ALL" COMO PARADIGMA DE PROJETO}

A prática projetual do espaço ainda hoje tem considerado apenas de modo circunscrito o fato de que uma pessoa atravessa, ao longo da vida, diversas fases, que compreendem diferentes condições de saúde e "eficiência". Algumas limitações, como aquelas relacionadas à locomoção, são circunstanciais e experimentadas por todos indiscriminadamente, seja na infância ou na velhice, como resultado dos efeitos processuais e incontornáveis da passagem do tempo. Essa escassa consideração, que não é exclusiva de arquitetos ou projetistas, pode ser vista como uma das causas da segregação espacial que encontramos nos edifícios e na cidade como um todo.

A mudança dessa perspectiva está relacionada ao surgimento das primeiras discussões em torno do conceito de Universal Design - ou Design for All -, na década de 1980, quando se reconheceu a necessidade de superar projetos pensados a partir de standards idealizados. Para esse efeito, o projeto de acessibilidade teria que se desenvolver de modo integrado e não de modo paralelo ou complementar ao projeto de arquitetura e ao projeto urbano, sendo capaz de produzir resultados em favor de um grupo de usuários cada vez mais ampliado.

Essa questão aparentemente simples não se converteu, todavia, em uma práxis universalmente difundida. As ações direcionadas a promover a acessibilidade de um modo não circunscrito a um público restrito acabam ainda hoje por reproduzir modelos ainda inadequados e não completamente inclusivos de acesso, que podem prejudicar os utentes não apenas pela ausência, mas também pelo excesso de um aparato técnico que possa confundir ou mesmo provocar involuntariamente formas sutis de segregação. 


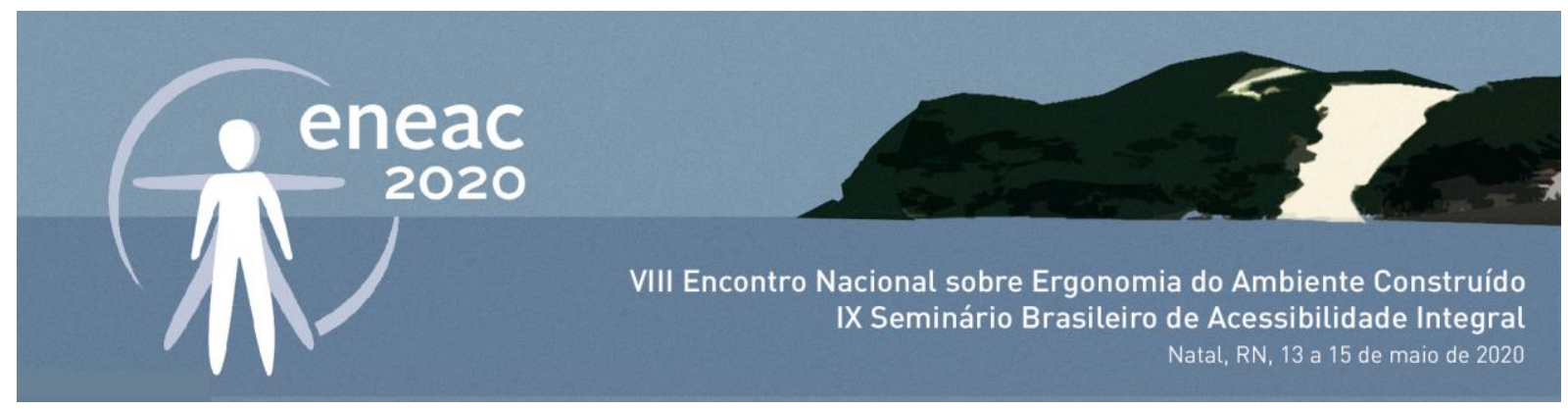

A Figura 1 ilustra as fases atravessadas pelo tema da acessibilidade, cada uma delas sintetizada por um termo e uma imagem correspondente. A primeira fase corresponde a um momento em que não eram claramente conhecidas as necessidades das pessoas com deficiência, que, até então, formavam um grupo "invisível" para a sociedade como um todo. Em um segundo momento, passa-se da exclusão à segregação que, por sua vez, parte de um conhecimento restrito do problema da acessibilidade e propõe soluções circunscritas que acabam por delimitar ou confinar em um âmbito específico uma "categoria" de pessoas. A integração apresenta uma abertura maior para o acolhimento de pessoas consideradas "diferentes", mas mantendo ainda o acento na diferença em vez de sublinhar aquilo que é comum e possível a todos, como enfatiza a proposta de inclusão.

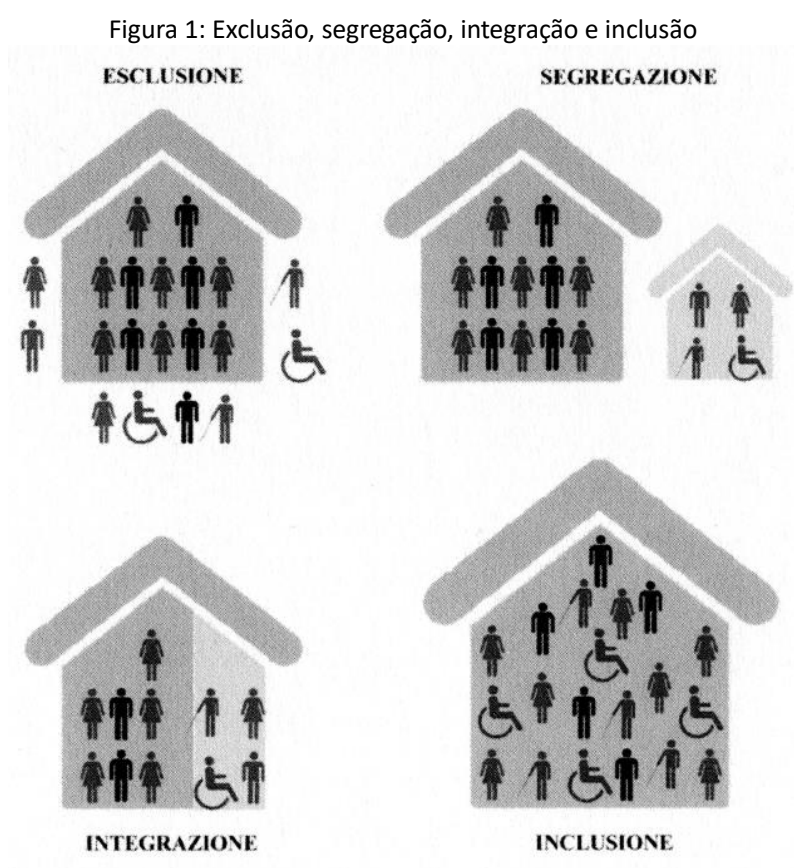

Fonte: Guidolin; Tatano, 2016.

\section{O ESPAÇO PENSADO PARA TODOS E A NORMA}

Enquanto persiste uma compreensão social ainda pouco difundida sobre o problema da acessibilidade e da inclusão, cabe, sobretudo à legislação, a tarefa de garantir a produção de um espaço que pode ser fruído por todos. É a legislação que constitui hoje a base de garantias mínimas de acesso universal, sobretudo no que diz respeito ao espaço público. Entretanto, dada a complexidade envolvida no assunto, é difícil assegurar que a prescrição de parâmetros técnicos possa equacionar, nos vários níveis de dificuldade em que se apresentam, todos os problemas enfrentados no âmbito do projeto de acessibilidade.

Para nos determos em apenas um exemplo, lembremo-nos de que a NBR 9050/2015 (ASSOCIAÇÃO BRASILEIRA DE NORMAS TÉCNICAS, 2015, p. 84) recomenda, pensando no conforto e privacidade de pessoas com deficiência que necessitem ser acompanhadas por pessoas do sexo oposto para utilizar instalações sanitárias em edificações públicas, que tais instalações sejam dotadas de acesso independente com relação às demais unidades sanitárias. Essa determinação implica, entretanto, no 


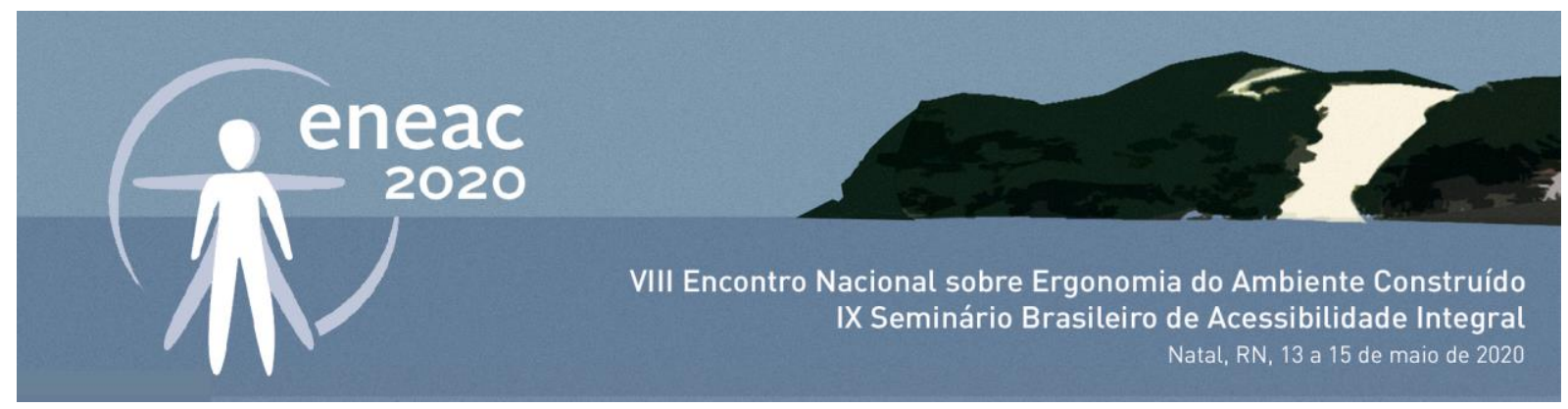

fato de que - no caso amplamente difundido da existência de apenas uma unidade adaptada para pessoas com deficiência, e estando tal unidade separada das unidades sanitárias convencionais - isso enfatiza a ideia de segregação, ainda que de modo não intencional. Nesse caso, uma solução de projeto que permitisse acesso reservado de um acompanhante de outro sexo sem eliminar a conexão espacial da unidade sanitária adaptada às demais instalações seria uma solução preferível, mas que dependeria de uma adequada interpretação da norma que, a seu turno, está relacionada ao nível de informação e sensibilização do projetista com relação ao problema.

Além da abertura a interpretações que podem ir de encontro ao objetivo de trabalhar de modo inclusivo, a regulamentação de parâmetros técnicos de acessibilidade é frequentemente acusada de excessivo rigor - o que acaba por dificultar a elaboração dos projetos por determinar a utilização de standards frequentemente inatingíveis, sobretudo quando nos referimos à adaptação de construções preexistentes. Essa crítica assume um tom irônico e ao mesmo tempo divertido no romance policial escrito por Giuseppe Davanzo (2001), então professor da disciplina Arquitetura de Interiores, no Instituto Universitário de Arquitetura de Veneza. Em Quella Notte ai Tolentini, todos os docentes do Instituto são transformados em personagens de uma trama em que o professor mais comprometido com o tema da eliminação de barreiras arquitetônicas é assassinado. A morte da personagem funciona como uma catarse para os outros docentes, embaraçados com o seu discurso politicamente correto recorrente e não tão sensíveis à necessidade de conduzirem os projetos de suas disciplinas conforme recomendações de uma norma então considerada "mal elaborada" e "ultrajante".

Se é verdade que a legislação segue com seu papel de assegurar garantias mínimas para a promoção de um espaço que possa ser realmente vivenciado por todos, não é menos verdadeiro que atua em um ambiente cultural ainda não completamente familiarizado com o tema, e ainda relativamente hostil a qualquer suposta ameaça à liberdade do processo criativo com a qual se identifica a elaboração do projeto de arquitetura. Por outro lado, não deixa de ser um contrassenso que o diferencial capaz de fazer avançar na prática quotidiana aquilo que no papel permaneceria apenas "letra morta" seja o envolvimento mútuo e solidário de projetistas, usuários e da administração pública na busca de soluções ao mesmo tempo satisfatórias e possíveis para os problemas enfrentados.

\section{ACESSIBILIDADE NAS PONTES E VENEZA}

Veneza pode ilustrar, na prática, o desafio de equacionar o problema do acesso universal ao espaço da cidade e a relação entre a legislação e as soluções apresentadas na tentativa de eliminar barreiras arquitetônicas. A especificidade da cidade no que diz respeito às suas características morfológicas requer, muitas vezes, intervenções específicas para as quais as prescrições padronizadas ou não conseguem ser implementadas ou não são capazes de dar resultados à altura do que é esperado.

Se nos detivermos apenas nas dificuldades enfrentadas pelas pessoas que possuem algum déficit de mobilidade, é fácil identificar que, em uma escala urbana, as pontes se constituem em um dos principais obstáculos arquitetônicos a serem superados na cidade, uma vez que a maioria é dotada de degraus que as fazem, no nível de deslocamento pedonal, funcionar como escadas. São mais de 400 pontes distribuídas por toda a cidade, o que torna praticamente inevitável não encontrá-las pelo caminho, seja qual for o percurso a ser cumprido. 


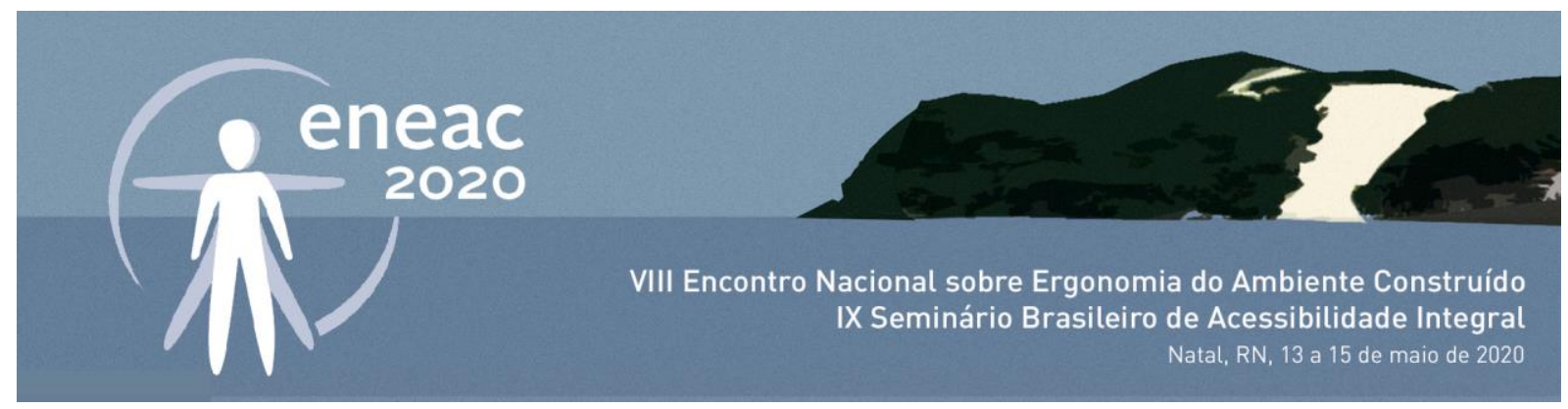

Entre as primeiras tentativas de solucionar o problema de acessibilidade das pontes de Veneza, merece destaque a experiência realizada com a instalação de meios mecânicos, dentre os quais se destacavam - em número - as cadeiras elevatórias. Não obstante estarem completamente de acordo com as recomendações previstas na legislação italiana sobre acessibilidade, não resultaram em experiências satisfatórias, de modo que, em 2009, a administração pública decidiu remover todas as nove unidades instaladas em pontos diversos da cidade. $\mathrm{O}$ escasso funcionamento e mal estado de conservação das cadeiras elevatórias, frequentemente associadas ao tema do mau uso dos recursos públicos, foram diversas vezes alvo de críticas na imprensa local (Figuras 2 e 3 ).
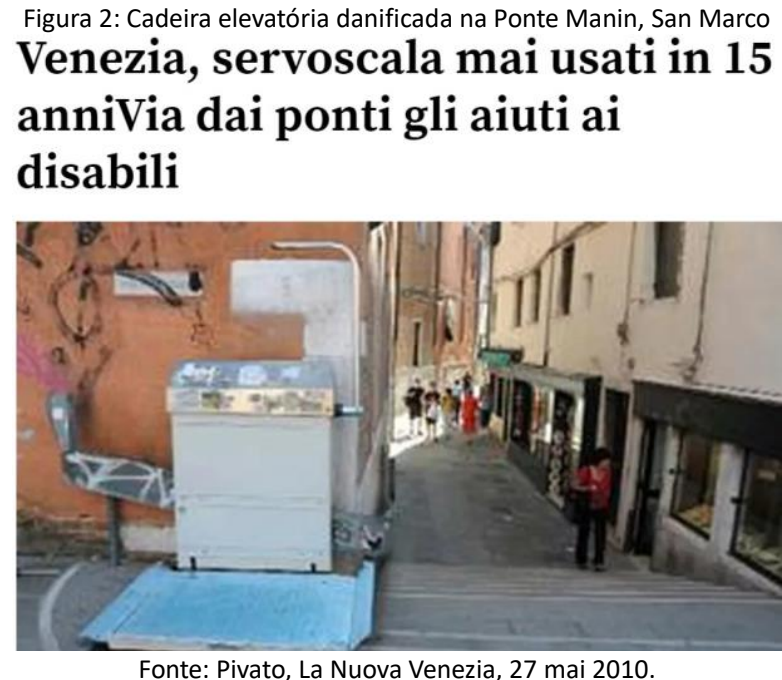

Figura 3: Cadeira elevatória danificada na Ponte della Crea, Cannaregio
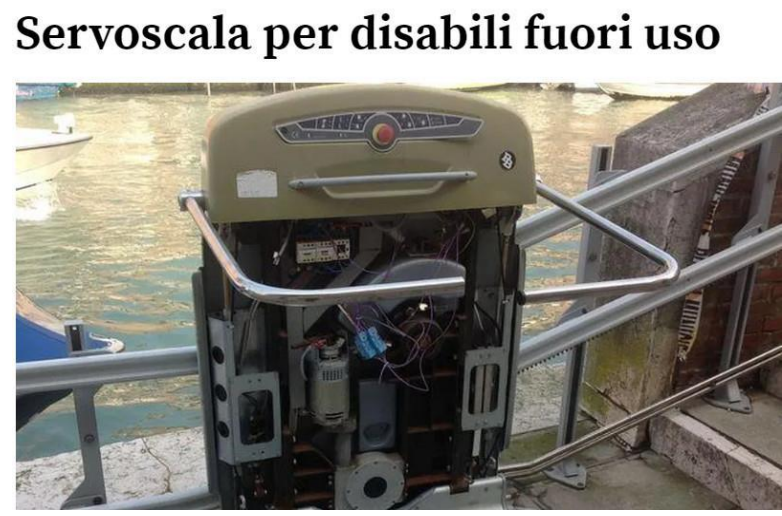

Fonte: Petricca, La Nuova Venezia, 6 mar 2013.

De origem mais recente, mas ainda no conjunto das propostas que utilizavam meios mecânicos como recurso para garantir acessibilidade às pontes, o projeto do engenheiro Giovanni Cocco para a Ponte Longo recebe aprovação para a instalação de dois elevadores encastrados em estruturas de aço e vidro, como parte de uma intervenção geral de restauro, concluída em 2006. Os elevadores ainda não foram desmontados, mas sofrem críticas semelhantes àquelas direcionadas às cadeiras elevatórias (Figura 4), além da acusação de provocar um impacto visual não compatível com a preservação das características morfológicas do entorno (GUIDOLIN; TATANO, 2016, p. 23). 


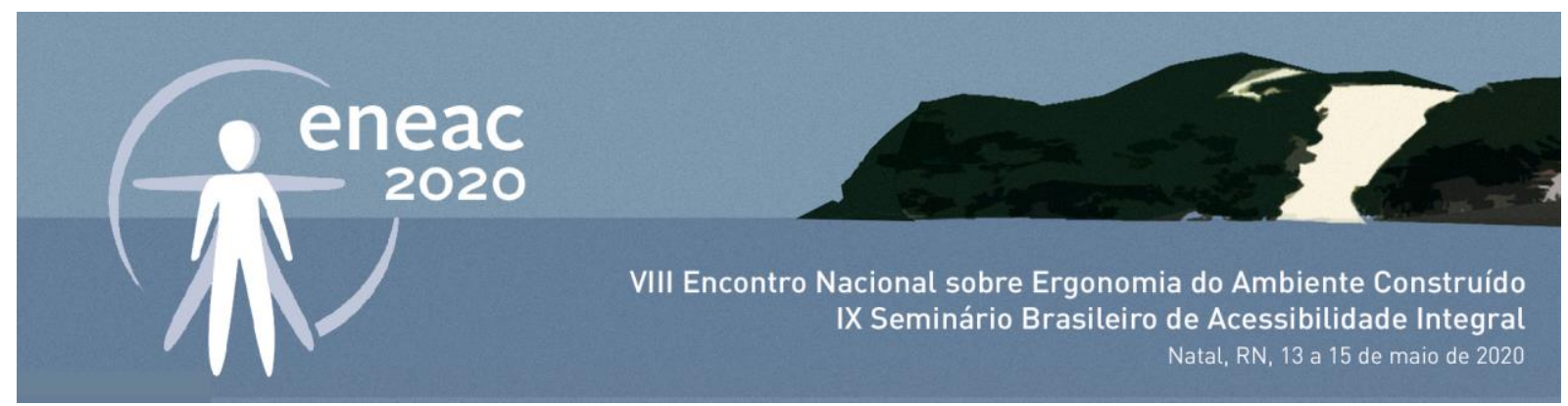

Figura 4: Manchete sobre a Ponte Longo na Giudecca

\section{Ponte della Giudecca come Calatrava: ascensore "milionario" da rimuovere}

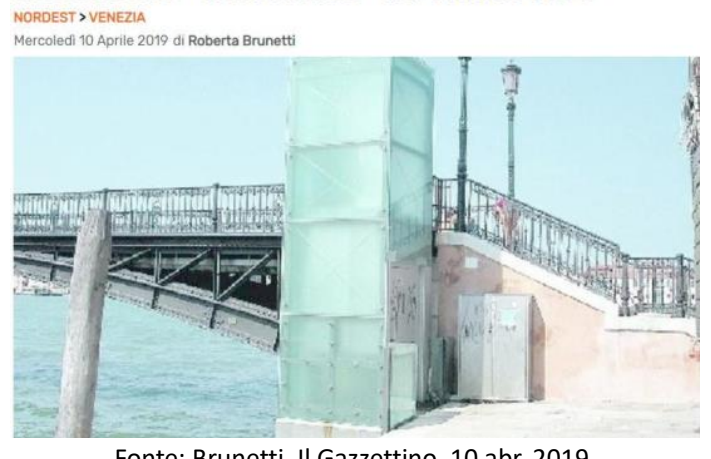

Fonte: Brunetti, II Gazzettino, 10 abr. 2019.

Com a aprovação do Plano para a Eliminação das Barreiras Arquitetônicas (PEBA), no ano de 2004, pelo Conselho Comunal, foi dado mais um passo na busca de encontrar soluções para facilitar a utilização das pontes da cidade. Reconhecendo a impossibilidade de intervir sobre o conjunto total de pontes, o plano de acessibilidade de Veneza se articula, de modo muito próximo, com o plano de mobilidade urbana, de forma que o transporte aquático assume uma importância central na garantia de acesso a amplas áreas da cidade. Partindo dessa premissa, foi elaborado, em 2008, um mapa geral, em que as áreas marcadas em verde-escuro e verde-claro representam, respectivamente, regiões acessíveis por transportes aquáticos públicos e particulares, adaptados a necessidades especiais de utilização. No mesmo mapa, as áreas assinaladas em vermelho correspondem às zonas "inacessíveis" (Figura 5). No momento em que foi elaborado, o mapa indicava a presença de seis pontes cujo atravessamento poderia ser feito com o auxílio de cadeiras elevatórias (círculos brancos) e cinco pontes sobre as quais a administração pública havia realizado obras de adaptação para melhorar as condições de acessibilidade (círculos negros).

Figura 5: Mapa Veneza Acessível. Situação da cidade em 2008

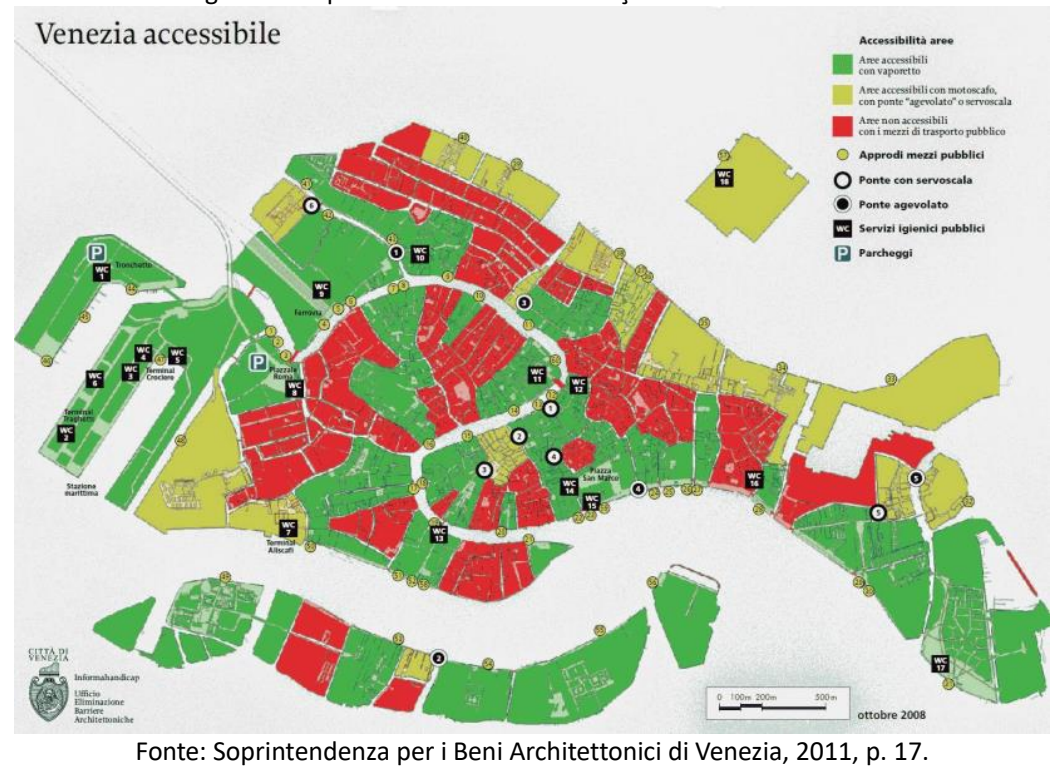




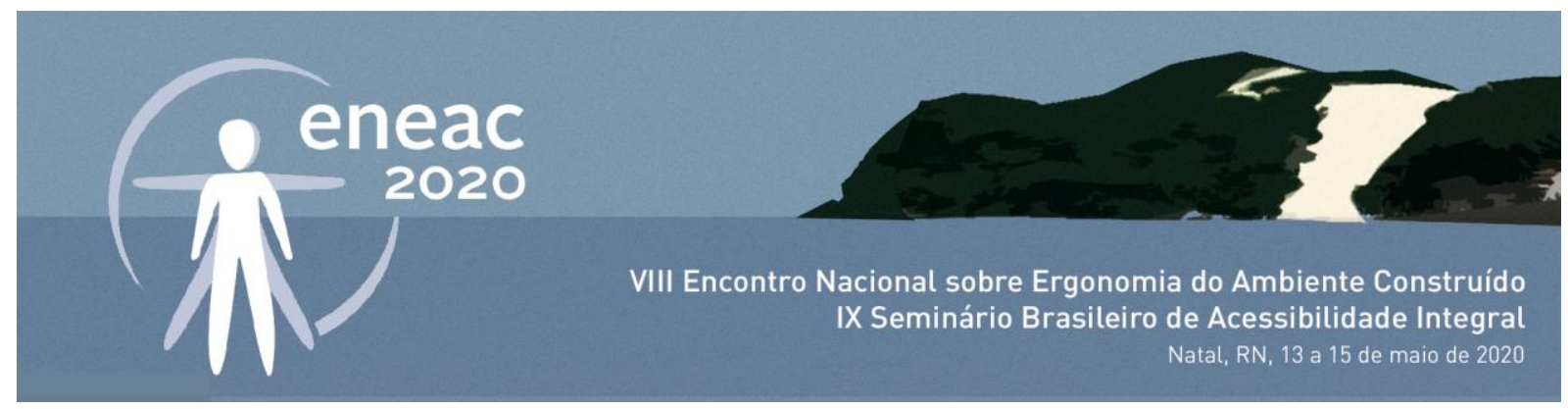

Em 2011, sete anos depois da elaboração do PEBA, o relatório técnico elaborado pela Superintendência dos Bens Arquitetônicos de Veneza para apresentar uma solução alternativa para o problema de acessibilidade na cidade define como centro de suas ações o conceito de Universal Design, cujo pressuposto essencial seria o de

\begin{abstract}
ter deslocado a perspectiva de uma cultura projetual cuja única obrigação, em termos de acessibilidade, era adequar-se à normativa realizando soluções "exclusivas" e portanto frequentemente discriminatórias, para uma em que a cultura projetual saiba criar um ambiente acessível, isto é, fruível de modo seguro, confortável e qualitativamente melhor, por parte de qualquer um, uma cultura que tem como sujeito a assim chamada utilização ampliada (SOPRINTENDENZA PER I BENI ARCHITETTONICI DI VENEZIA, 2011, p. 4-5, tradução livre).
\end{abstract}

O mesmo relatório registra, ao fazer referência a experiências testadas anteriormente, a "escassa funcionalidade e pouca confiabilidade" dos meios mecânicos para tornar a cidade mais inclusiva. Com base nessa constatação, a instalação de rampas passa a ser considerada pelo ente público a solução mais adequada para superar desníveis por apresentar, em consonância com o princípio fundamental do Universal Design, a vantagem (1) de não estigmatizar o utilizador; (2) de apresentar flexibilidade de uso ao permitir que o utente escolha cumprir o percurso a partir da rampa ou da escada pré-existentes; (3) de permitir um uso simples e intuitivo; (4) de não necessitar de instruções ou informações para o sua correta utilização; (5) de minimizar os riscos de acidentes; (6) de necessitar de um esforço físico reduzido por parte do utilizador; e, por fim, (7) de não necessitar de elaboração nem de execução de projetos específicos para garantir a sua utilização (SOPRINTENDENZA PER I BENI ARCHITETTONICI DI VENEZIA, 2011, p. 7-8).

Além das vantagens relacionadas ao projeto universal, a rampa apresentaria, quando comparada aos meios mecânicos já experimentados no espaço público da cidade, a vantagem de possuir instalação e manutenção simplificadas e com menor custo, além da possibilidade de ser utilizada de modo a não comprometer a autenticidade do edificado precedente. $O$ desafio passa a ser então projetar rampas com a inclinação máxima admitida pela normativa italiana: máximo de $8 \%$ para as novas construções e $12 \%$ em contextos preexistentes, já que na maioria dos casos a instalação de tais rampas se mostra incompatível com a morfologia urbana da cidade. Alberto Arenghi resume desse modo o problema:

A questão de fundo reside no fato de que, para obter a inclinação de $8 \%$, ocorre um longo desenvolvimento linear da rampa o que não apenas tem um impacto estético pouco aceitável, mas, em muitos casos, provoca uma obstrução do espaço adjacente ao ponto de interferir no acesso aos edifícios (ARENGHI, 2012, p. 32, tradução livre).

Na tentativa de contornar essa limitação, as ações se voltam para a sistematização de soluções alternativas que possam se adaptar às condições específicas do lugar. 0 mesmo autor, que fez parte da equipe de consultores das experiências realizadas para o efeito, indica a via de experimentação: “o único caminho viável é aumentar a inclinação sem que a rampa se torne 'impraticável' e perigosa, sobretudo na descida" (ARENGHI, 2012, p. 32, tradução livre). A iniciativa é amparada pela normativa técnica nacional, sobretudo pelo Decreto Ministerial no 236/1989 e pelo Decreto Presidencial no 503/1996ii, que assinalam, no campo da acessibilidade, a flexibilização do teor predominantemente impositivo da norma, ao permitir que o projetista proponha soluções diferentes dos parâmetros especificados, desde que garanta a obtenção de resultados análogos ou melhores em termos de eficiência e qualidade da intervençãoiii. Arenghi $(2012$, p. 32) resume essa abertura como passagem de "leis prescricionais a leis 'prestacionais"' (grifo nosso). 


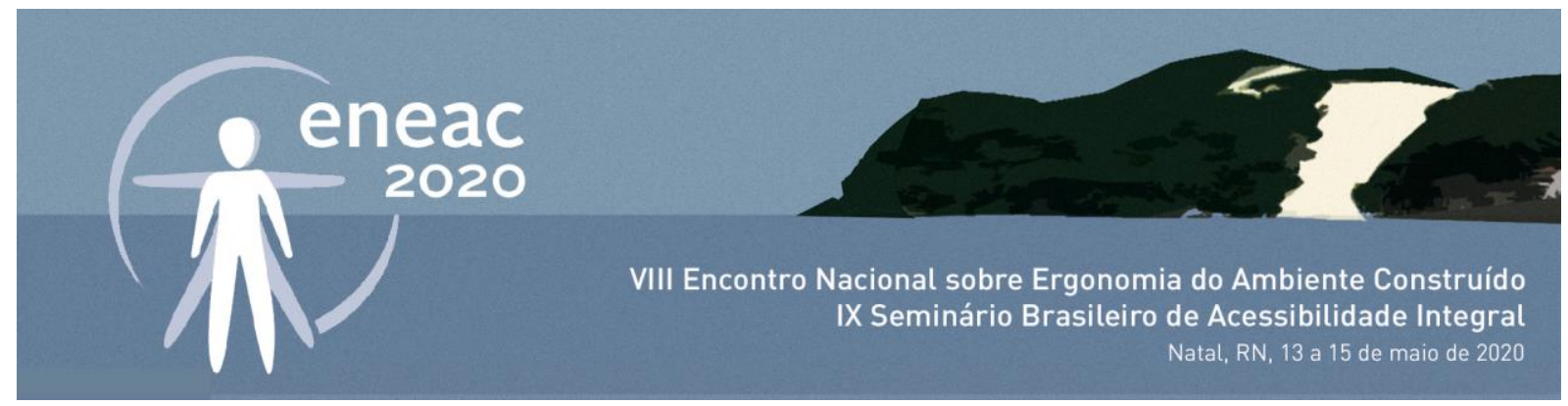

\subsection{O "gradino agevolato" ou "degrau facilitado" como solução experimental de projeto}

Esse princípio, que traduzo livremente como "degrau facilitado", é resultado de experiências realizadas a partir do final da década de 1980 no processo de adaptação das pontes de Veneza a melhores condições de fruição. Consiste fundamentalmente na composição de planos inclinados que se articulam entre si por um pequeno desnível vertical chanfrado ou boleado, permitindo assim a superação de uma certa altura de modo mais confortável do que permite uma escada e ocupando um espaço consideravelmente menor que uma rampa contínua.

O princípio do "degrau facilitado" pode se materializar de diversas maneiras, de forma tal que os efeitos de sua utilização podem ser amplamente diferenciados, tanto no que diz respeito à forma quanto no que se refere à eficiência. Na tentativa de sistematizar os resultados da aplicação desse princípio, o Serviço de Eliminação de Barreiras Arquitetônicas (EBA) da cidade de Veneza realizou testes práticos com o objetivo de verificar a adequação funcional de seis variações de "rampa facilitada". O experimento foi realizado de dezembro de 2008 a julho de 2010, utilizando protótipos constituídos por uma mesma estrutura metálica sobre a qual podiam ser colocadas peças de metal moldadas conforme cada um dos modelos selecionados para teste. Os protótipos apresentavam módulos componíveis com $60 \mathrm{~cm}$ de projeção horizontal com igual inclinação (códigos vermelho e azul) ou módulos componíveis com $60 \mathrm{~cm}$ de projeção horizontal com inclinação diferenciada para cada metade do módulo (códigos verde, amarelo, azul e violeta). Em todos os casos, os módulos são intercalados por um pequeno degrau chanfrado com $7 \mathrm{~cm}$ de projeção horizontal e que varia entre $3 \mathrm{~cm}$ e $6 \mathrm{~cm}$ de altura.

Figura 6: Seção esquemática longitudinal dos protótipos de rampa com “degrau facilitado"

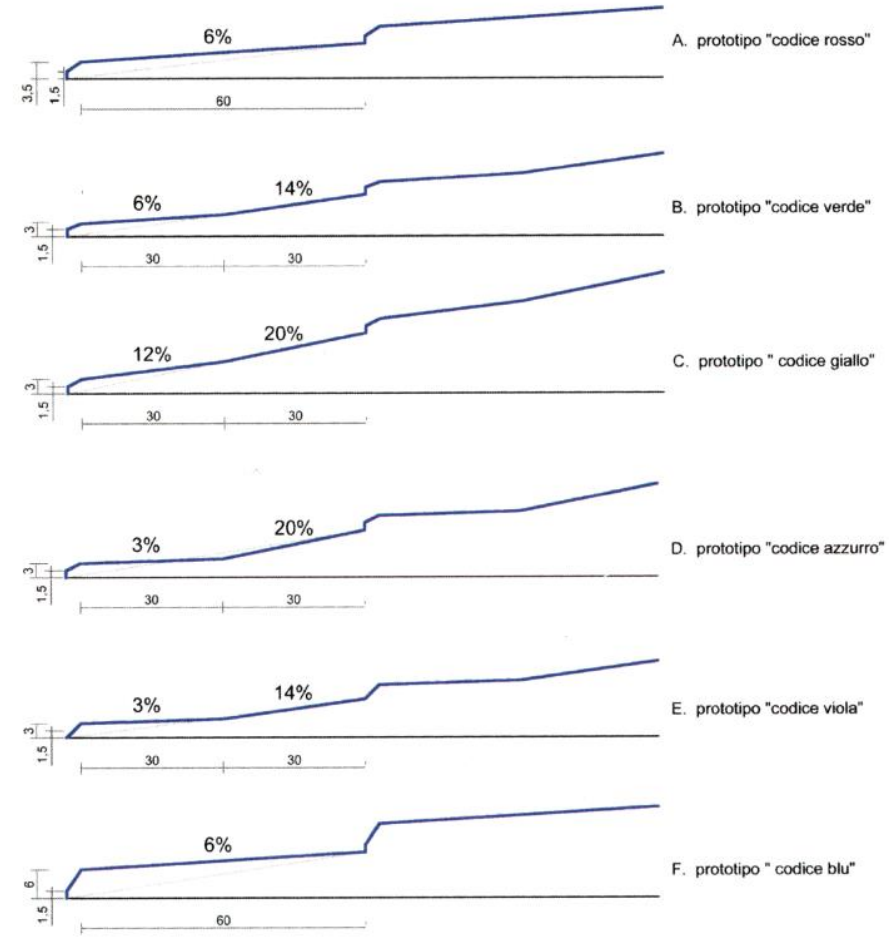

Fonte: Guidolin; Tatano, 2016. 


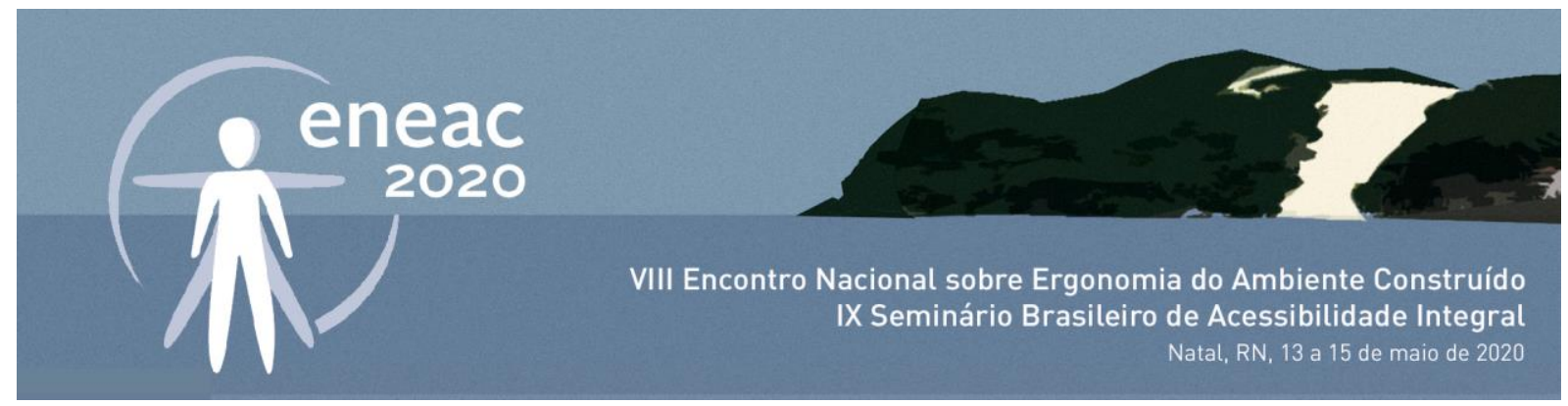

Os testes foram realizados por pessoas com deficiências motoras diversas, que usavam ou não cadeiras de rodas, pessoas com deficiência visual, pessoas afetadas por quadriplegia espástica e idosos. Foram utilizadas cadeiras de roda de acionamento manual e elétrico, sendo que, no primeiro caso, os utentes estavam sempre acompanhados. O público que assistiu aos experimentos possuía competências diversificadas. Entre os assistentes, estavam representantes do setor da saúde e assistência, como médicos e fisioterapeutas, e representantes de associações governamentais e não governamentais, envolvidos com vários aspectos do tema da acessibilidade.

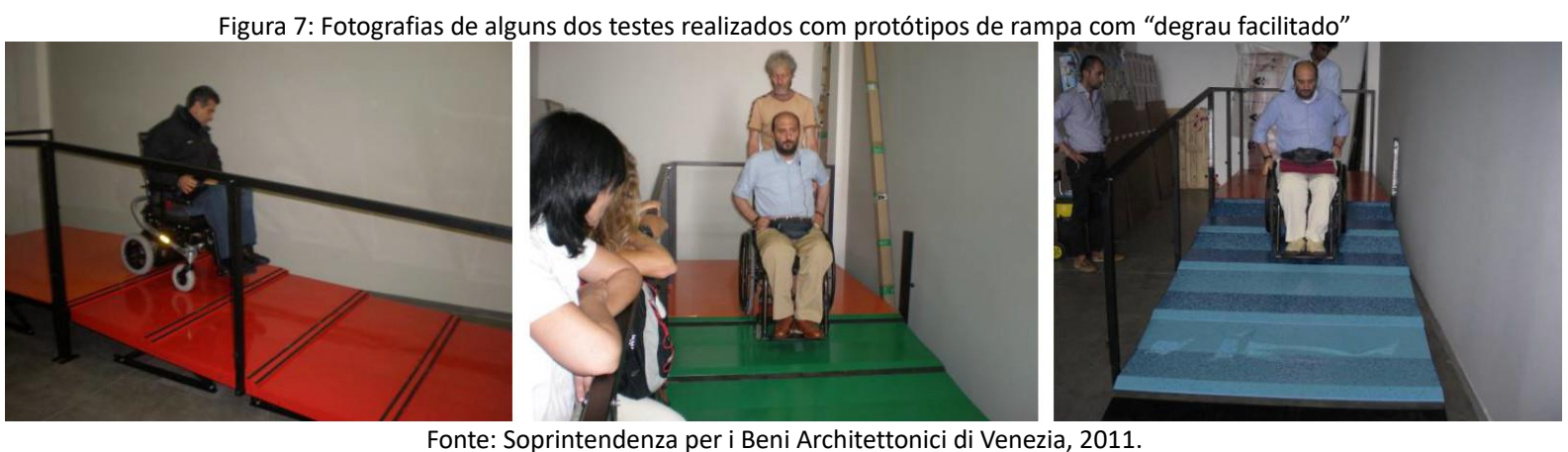

No final do experimento as tipologias geométricas que apresentavam dupla inclinação mostraram ser de mais fácil utilização quando comparadas àquelas que possuíam inclinação única, sobretudo por permitirem um atravessamento gradual, com múltiplas partidas a partir do trecho menos inclinado. Entre os modelos que combinavam módulos com inclinação diferenciada, o protótipo identificado como código verde revelou-se o mais confortavelmente percorrível por apresentar-se menos suscetível aos pequenos incidentes, sobretudo quando da utilização de cadeira de rodas com ou sem acompanhante. Esse modelo apresenta possibilidade de redução do desenvolvimento longitudinal da estrutura na ordem de $40,43 \%$ quando comparado a uma rampa "à norma" de inclinação igual a $8 \%$. A sua inclinação média final é de $13,4 \%$. Todos os dados apresentados são da Soprintendenza per $i$ Beni Architettonici di Venezia (2011, p. 15).

Figura 8: Seção esquemática longitudinal do protótipo de código verde com comparação com uma rampa de inclinação uniforme de 8\%
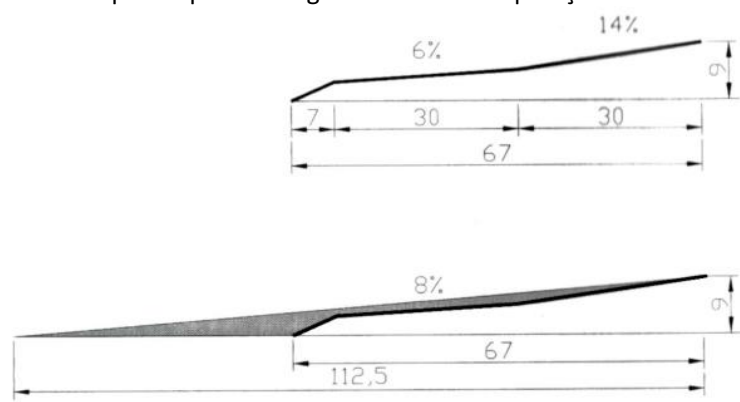

Fonte: Arenghi, 2012.

Ao abrigo da lei italiana, a experiência com os seis modelos de rampa ilustrados permite o enquadramento do "degrau facilitado" como solução de "acessibilidade equivalente" e como "melhoramento de uma solução pré-existente". Como não se trata de uma aplicação dos parâmetros 


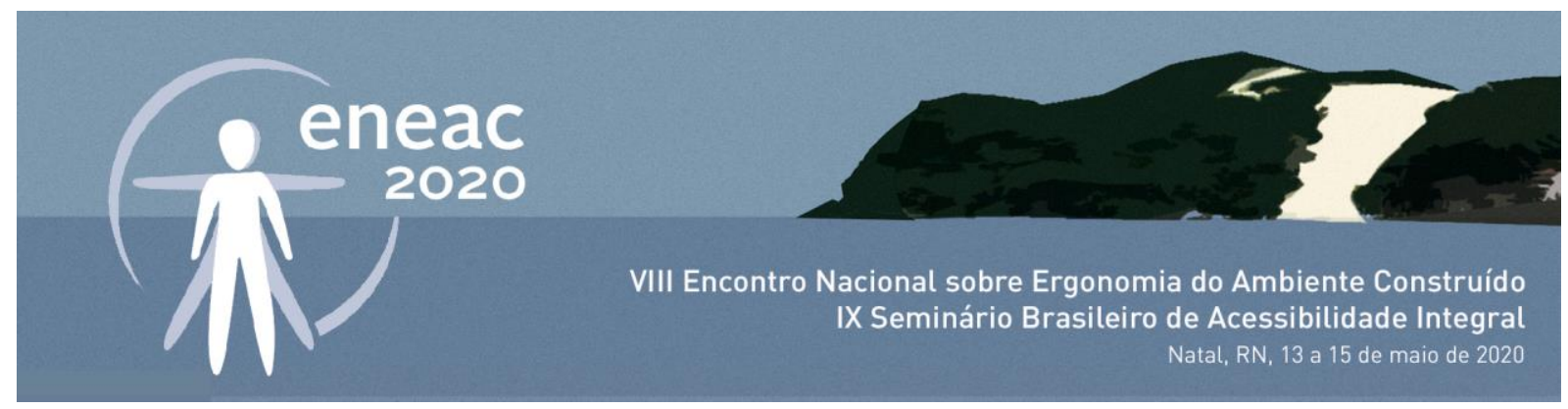

normatizados, o relatório técnico produzido para o efeito de sistematização dos resultados dessa experiência recomenda que a utilização do "degrau facilitado" no espaço público seja oportunamente assinalada por meio de uma adequada comunicação de sua especificidade e condição de "solução equivalente", bem como dos limites que impõe aos possíveis utilizadores. A Figura 9 ilustra a comunicação visual utilizada para o efeito na Ponte delle Guglie. A placa indica a inclinação média de $16 \%$ e declara em quatro idiomas a obrigatoriedade de acompanhante nos deslocamentos de cadeirantes.

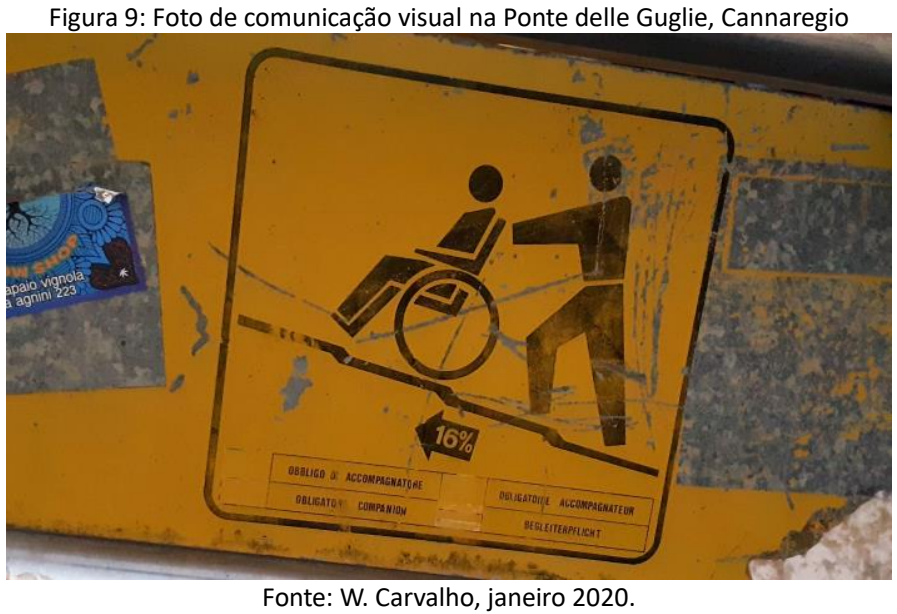

\subsection{Diferentes aplicações do "gradino agevolato" ou "degrau facilitado" na cidade de Veneza}

As intervenções de acessibilidade urbana em Veneza são resultado tanto de programas de restauro vinculados a ações de manutenção ordinária do espaço público quanto de intervenções patrocinadas diretamente pelo Serviço de Eliminação de Barreiras Arquitetônicas (EBA). Do primeiro plano operativo, são exemplo as obras realizadas na Ponte delle Guglie (Figura 10), na Ponte Longo (Figura 4) e na Ponte di San Pietro (Figura 12). O segundo grupo de intervenções se caracteriza por obras que não interferem na estrutura nem no desenho da ponte original. Possuem um caráter provisório, como os acréscimos de módulos inclinados de polietileno na Ponte di San Pietro (Figura 12) e nos trechos laterais da Ponte delle Guglie; ou reversível, como no caso da Ponte Papadopoli (Figura 14) e Ponte delle Sechere (Figura 16).

Sobretudo a partir de 2008, a Superintendência dos Bens Arquitetônicos de Veneza tem orientado projetos que privilegiam o critério do menor impacto sobre as construções preexistentes e sobre o contexto urbano, dada a necessidade de preservação e valorização do patrimônio arquitetônico da cidade. Desse modo, recomenda que, "em todos os casos, devem ser excluídas modificações estruturais das pontes e estudadas soluções com sobreposição que se configurem como elementos removíveis e claramente reconhecíveis com relação à estrutura original" (SOPRINTENDENZA PER I BENI ARCHITETTONICI DI VENEZIA, 2011, p. 20, tradução livre).

Os exemplos a seguir apresentam soluções projetuais diversas, executadas antes e depois da elaboração do Plano de Eliminação das Barreiras Arquitetônicas (PEBA), no ano de 2004. Servem para ilustrar, em uma pequena escala, os diferentes resultados que podem ser obtidos a partir da utilização de um único princípio de projeto: o "degrau facilitado" e os diferentes graus de adequação da solução às demandas apresentadas. 


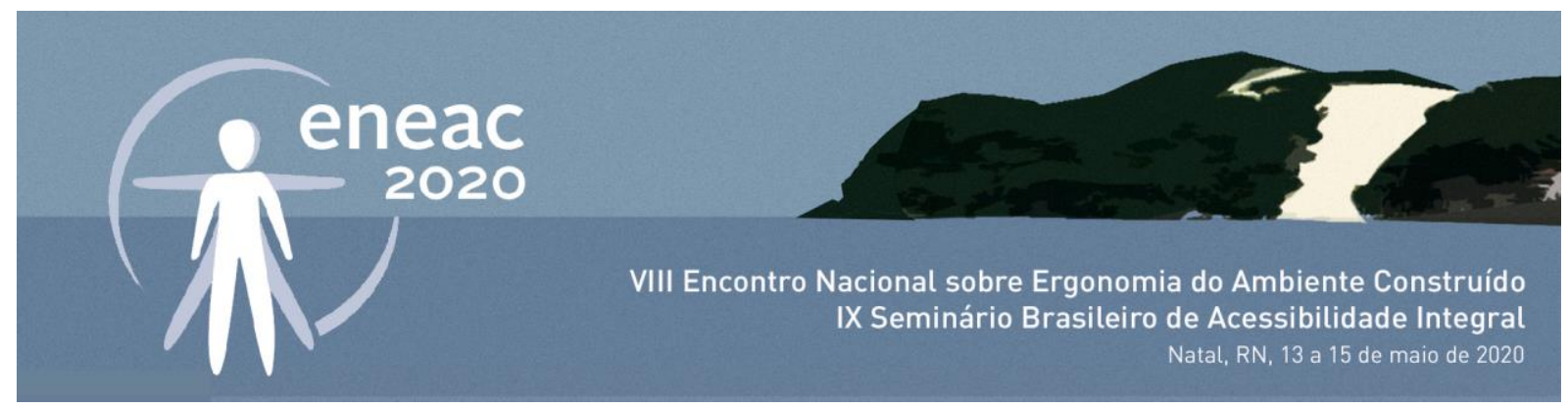

\subsubsection{Ponte delle Guglie, Cannaregio (1987)}

Essa é a primeira experiência de adaptação de uma ponte veneziana a melhores condições de acessibilidade que utiliza o princípio do "degrau facilitado". A intervenção é integrada à estrutura original e não apresenta ainda o caráter reversível destacado nos projetos mais recentes (Figura 10). A inclinação uniforme dos módulos sobrepostos e a inclinação média obtida de $16 \%$ aceleram o deslocamento na descida, de modo que, mesmo como "solução alternativa", é avaliada como insatisfatória ou passível de melhoramento. Em data posterior à intervenção, foram sobrepostos módulos inclinados de polietileno (Figura 13) aos degraus das escadas de acesso lateral à ponte, como forma de melhorar, ainda que parcialmente, as condições de acesso previstas no projeto.

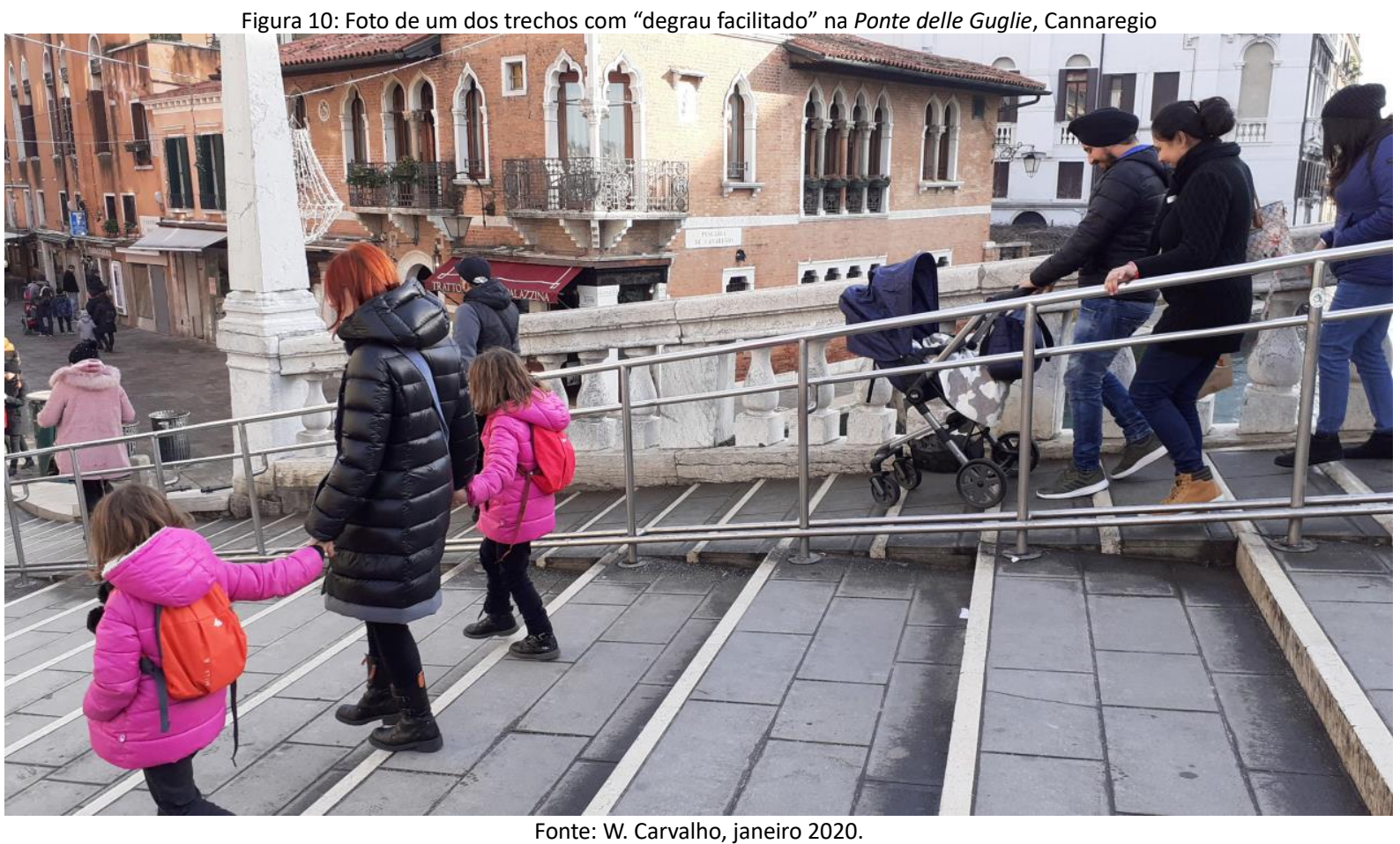

Figura 11: Seção longitudinal da Ponte delle Guglie com estrutura original assinalada em cor mais escura

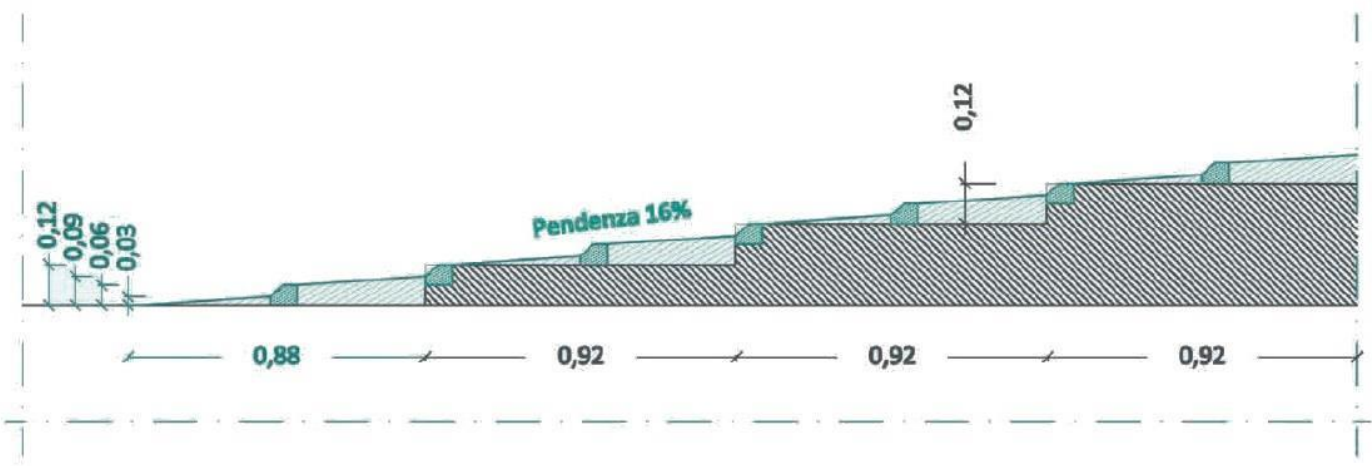

Fonte: Soprintendenza per i Beni Architettonici di Venezia, 2011. 


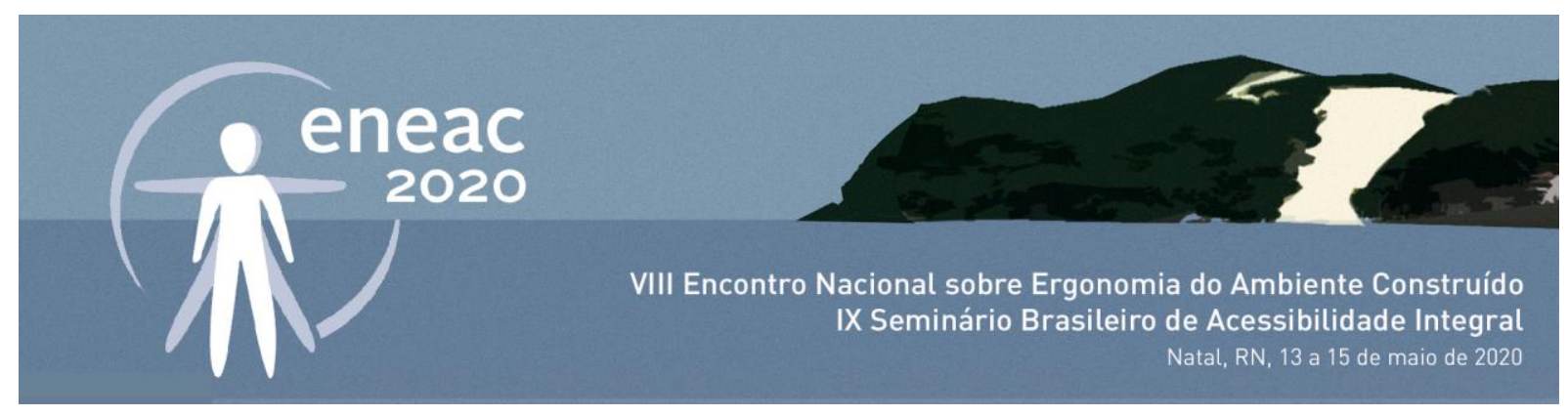

\subsubsection{Ponte di San Pietro, Castello (2008)}

Intervenção realizada por ocasião da reconstrução da ponte de 1883 a partir do projeto do arquiteto Michele Regini. O modelo de "degrau facilitado" consiste, nesse caso, na articulação de um módulo composto de um piso com inclinação aproximada de $11 \%$, articulado a um espelho de $8,5 \mathrm{~cm}$ de altura em pedra calcária branca com acabamento semicircular. Cada módulo permite a superação de um desnível de 16,5cm (INSULA, 2018). Segundo a Superintendência dos Bens Arquitetônicos de Veneza (2011, p. 48), a solução não garante uma adequada acessibilidade à ponte, razão pela qual foram acrescentados posteriormente os mesmos módulos de polietileno usados na Ponte delle Guglie.

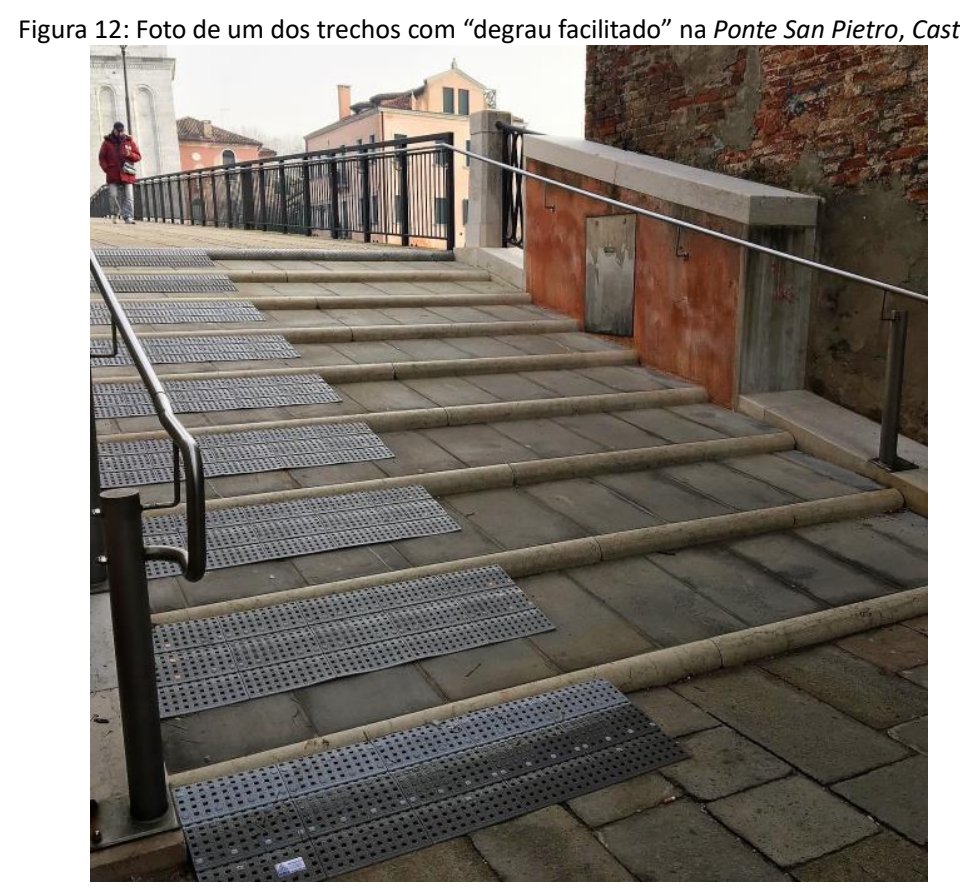

Fonte: W. Carvalho, janeiro 2020.

Figura 13: Esquema de montagem dos módulos de polietileno
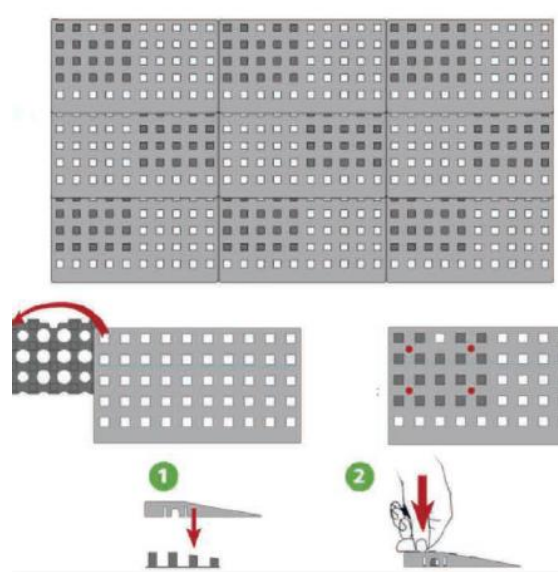

Fonte: Soprintendenza per i Beni Architettonici di Venezia, 2011. 


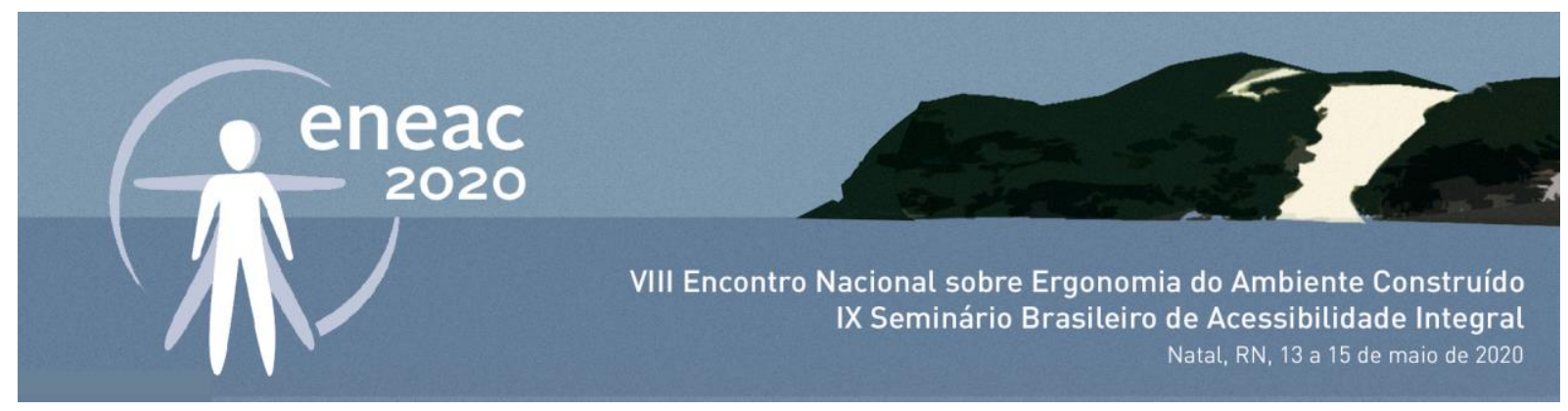

\subsubsection{Ponte Papadopoli, Santa Croce (2011/2016?)}

Obra de caráter reversível e passível de leitura diferenciada com relação à linguagem arquitetônica da ponte construída em 1933. A proposta consiste na sobreposição removível de uma estrutura modular de aço na qual são fixados os corrimãos laterais. O conjunto funciona de modo independente da estrutura original da ponte, apesar de o contato com piso original ser mantido. Os corrimãos garantem tanto a conexão quanto a autonomia da intervenção, que mantém intocado o guarda-corpo antigo executado em pedra da Ístria. Projeto do arquiteto Alberto Torsello.

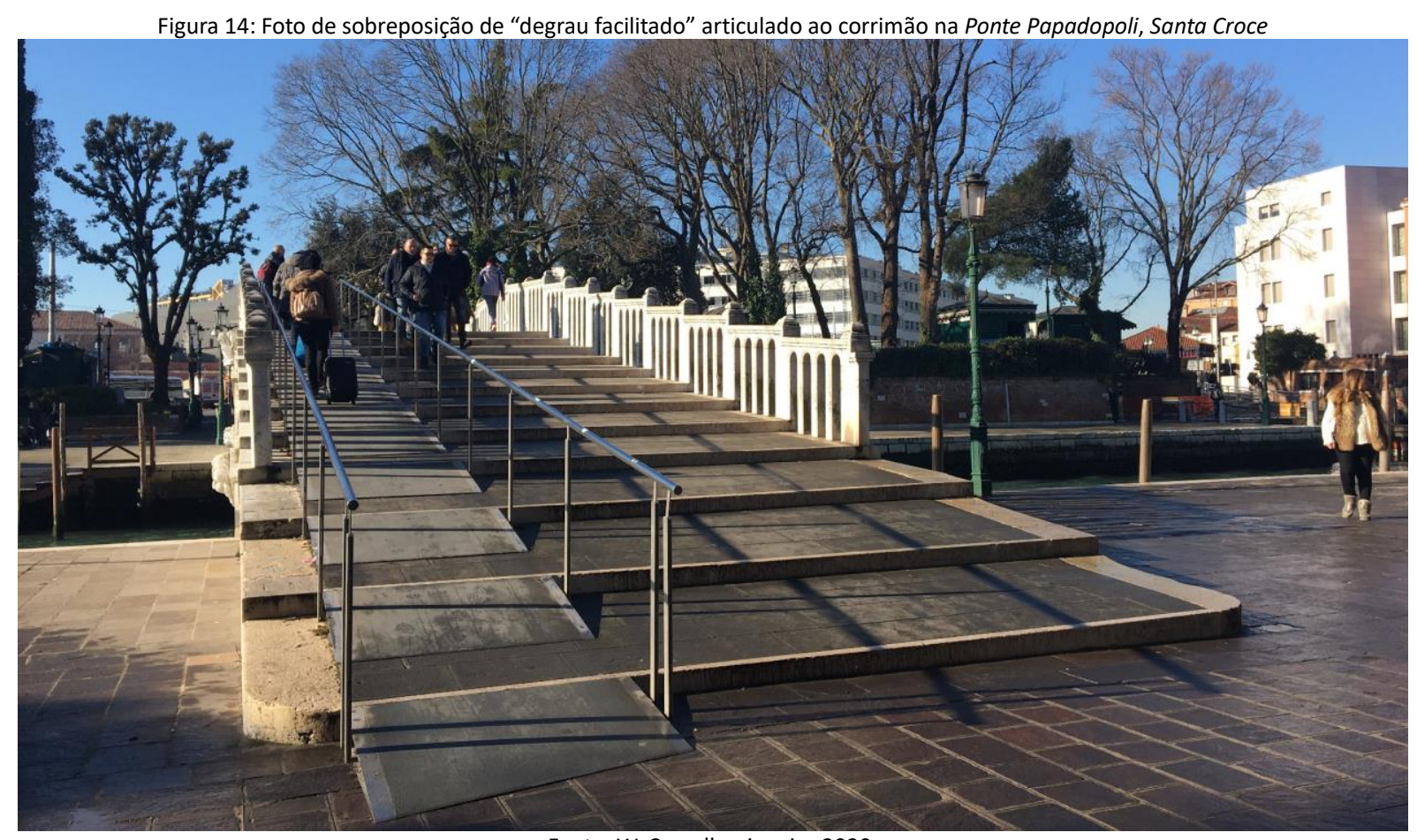

Fonte: W. Carvalho, janeiro 2020.

Figura 15: Vista superior e seção longitudinal do módulo de aço sobreposto aos degraus da Ponte Papadopoli
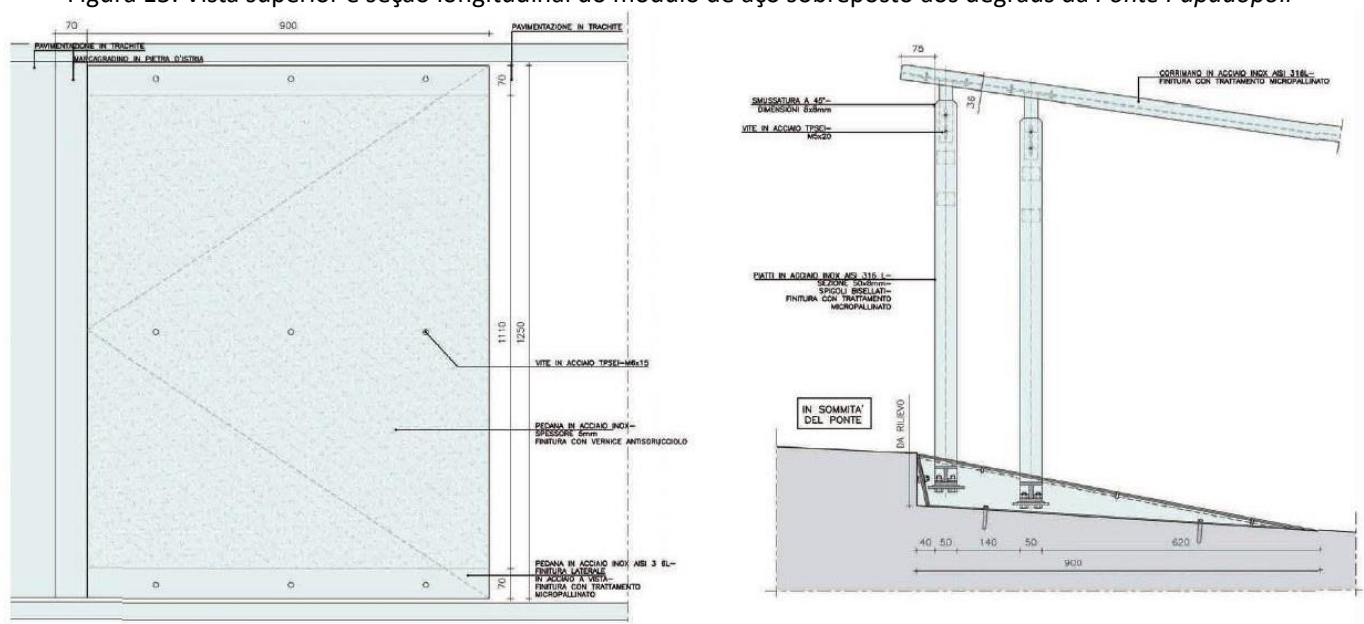

ISTA DaURALTO DELUA RAMPA, SCALA 1:10

Fonte: Soprintendenza per i Beni Architettonici di Venezia, 2011. 


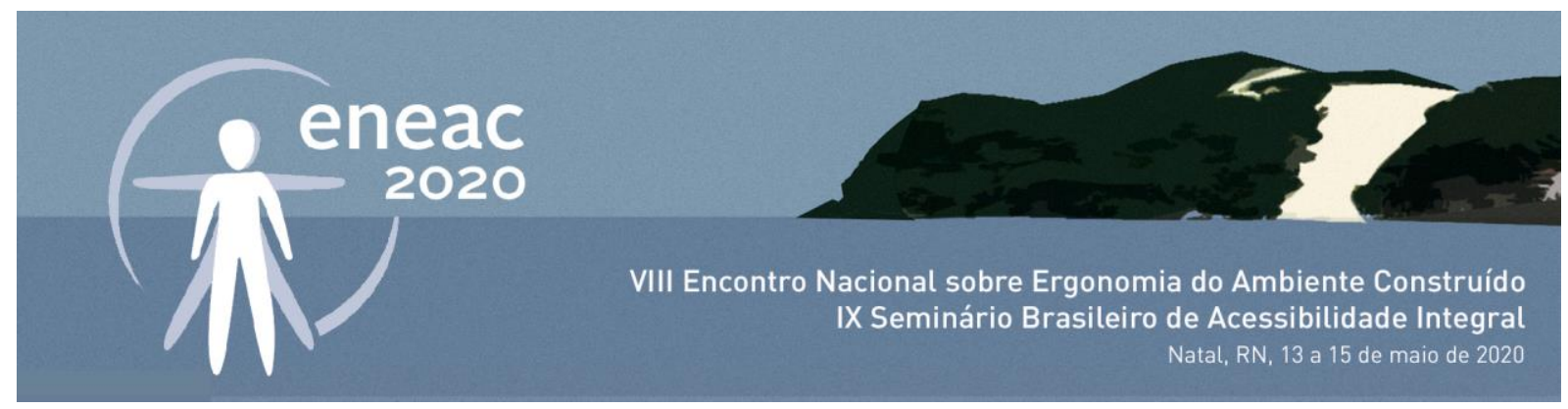

\subsubsection{Ponte delle Sechere, Santa Croce (2017)}

Como o exemplo anterior, a proposta consiste em solução reversível e independente daquela preexistente. Nesse caso, entretanto, o projeto prevê a "duplicação" da ponte a partir da sobreposição em suspensão de uma estrutura contínua de ferro apoiada pontualmente sobre a construção original e sobre o passeio. A "rampa facilitada" é apoiada sobre essa estrutura composta de dois trechos integrados, em que cada um serve de apoio para módulos de dupla inclinação. $\mathrm{Na}$ cota mais alta, é utilizado o protótipo de código azul, combinando inclinações de $4 \%$ e $20 \%$; na parte mais baixa, o protótipo de código verde, combinando inclinações de $6 \%$ e $14 \%$. Na obra executada, o degrau de $3 \mathrm{~cm}$ não é assinalado com material ou cor diferenciados, o que torna visualmente menos perceptíveis as mudanças de inclinação, que se alternam entre si. Projeto do arquiteto Tobia Scarpa.

Figura 16: Foto da articulação de dois modelos de "degrau facilitado" com dupla inclinação sobre a Ponte delle Sechere, Santa Croce

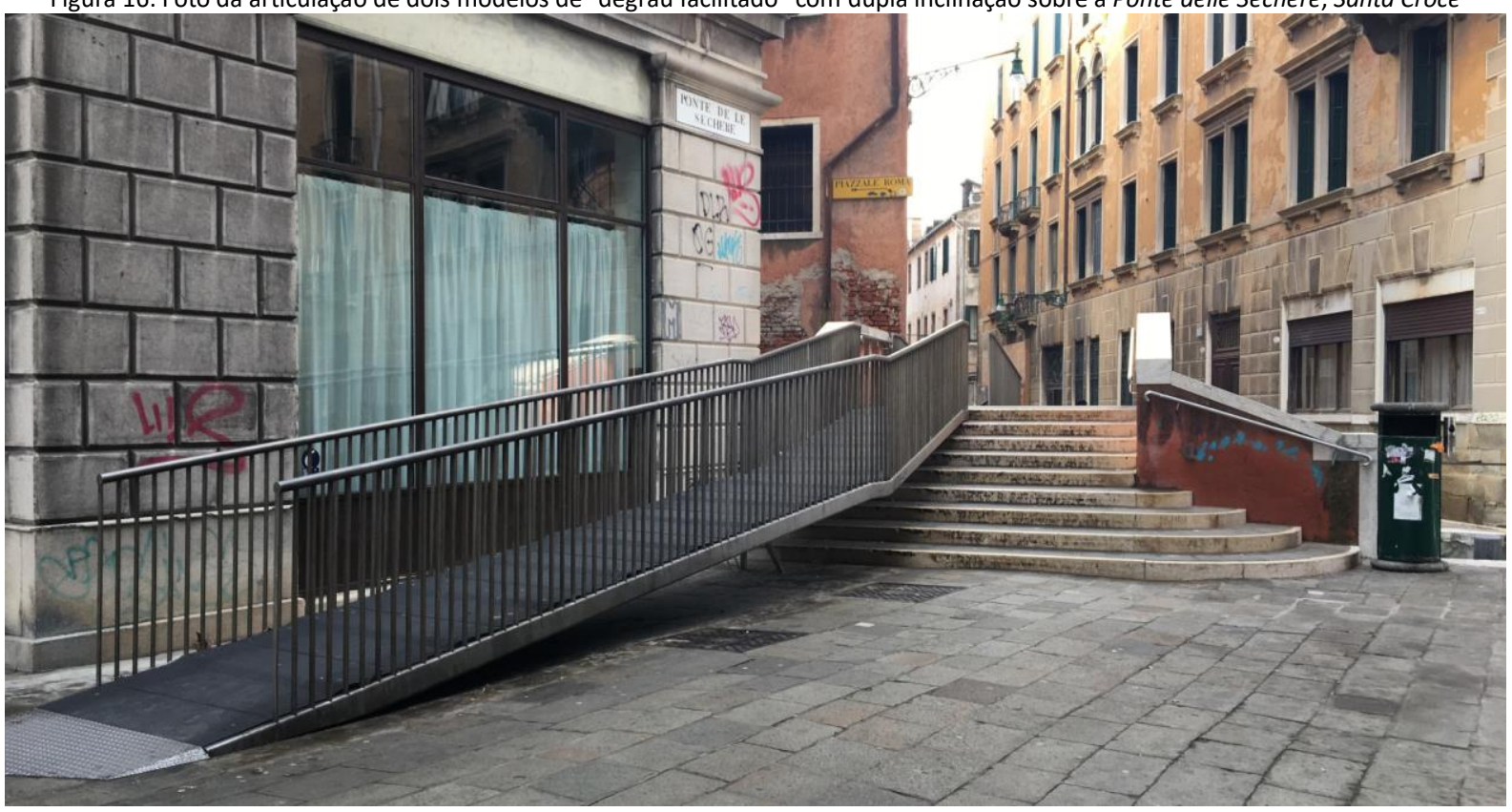

Fonte: W. Carvalho, janeiro 2020

Figura 17: Foto em detalhe do piso da rampa sobre a Ponte delle Sechere, Santa Croce

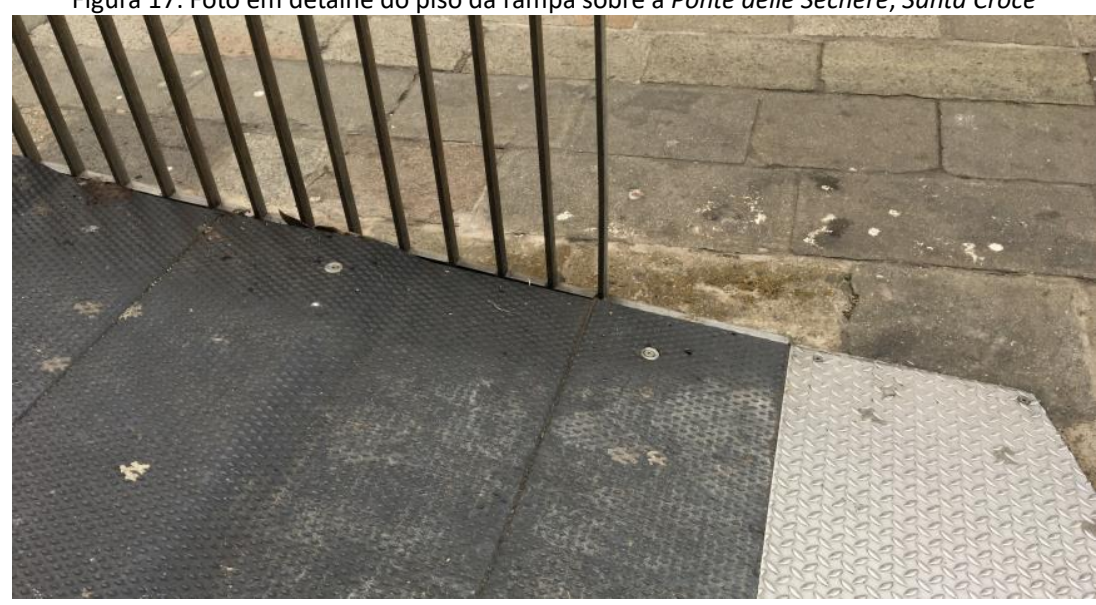

Fonte: Foto W. Carvalho, janeiro 2020. 


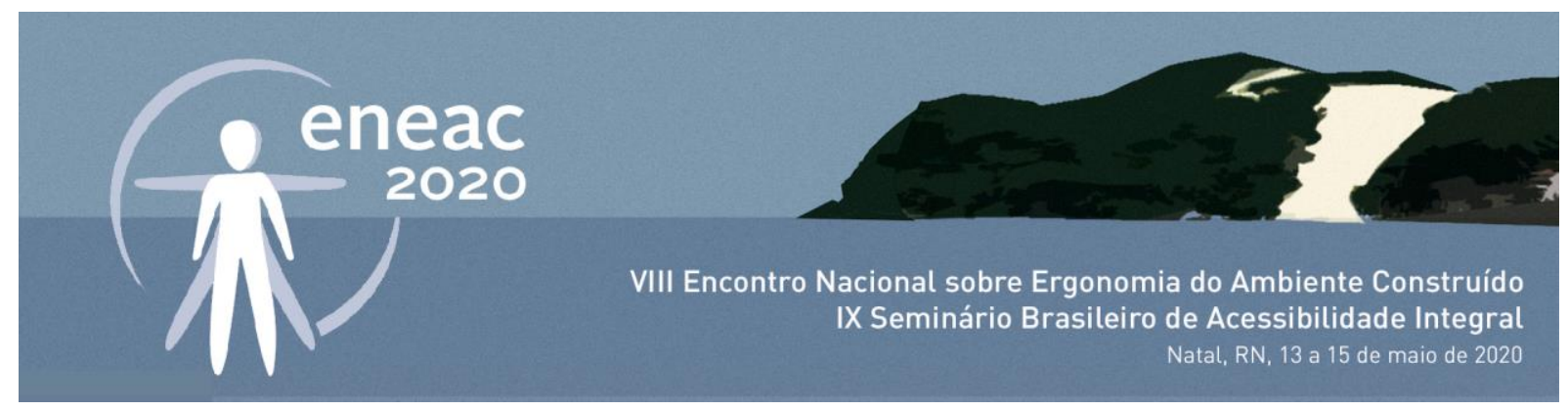

\section{CONSIDERAÇÕES FINAIS}

As pontes com degraus são um problema específico de acessibilidade da cidade de Veneza, motivo pelo qual as soluções apresentadas neste texto não têm o objetivo de divulgar modelos para aplicação prática em contextos diferentes daquele que o originaram. Por outro lado, a experiência veneziana nos permite encarar a construção de espaços acessíveis sob uma nova perspectiva, em que a norma pode funcionar como elemento agregador de múltiplas experiências, para além do seu intrínseco papel prescritivo.

Na medida em que pensar o edifício e a cidade para todos deixa de ser uma determinação puramente formal, não apenas a resistência dos profissionais diretamente envolvidos na aplicação dos parâmetros regulamentados em lei pode ser atenuada, como também aumentam as possibilidades de se encontrarem soluções adequadas e possíveis para os problemas enfrentados, ainda que em situações particularmente difíceis como as adaptações de espaços pré-existentes com interesse cultural relevante.

A experiência veneziana também serve para evidenciar o fato de que não basta estar de acordo com a normatização vigente para garantir a eficiência da solução de acessibilidade. A obtenção de resultados adequados ao problema requer estudos particulares e relativamente aprofundados não apenas sobre o objeto no qual se deseja intervir, mas sobre o impacto que a intervenção é capaz de proporcionar no entorno e a quantidade de usuários beneficiados em cada ação pontual. Todos esses fatores são importantes para fazer avançar o conhecimento sobre o tema da acessibilidade e para promover a construção de uma cultura de projeto que seja verdadeiramente inclusiva.

\section{REFERÊNCIAS}

ARENGHI, A. Accessibilità ai beni architettonici: il caso della rampa a gradino agevolato per i ponti di Venezia. In: GAROFOLO, I.; CONTI; C. Accessibilità e valorizzazione dei beni culturali. Milano: FrancoAngeli, 2012. p. 29-41.

ASSOCIAÇÃO BRASILEIRA DE NORMAS TÉCNICAS. NBR 9050: Acessibilidade a edificações, mobiliário, espaços e equipamentos urbanos. Rio de Janeiro. 2015.

DAVANZO, G. Quella notte ai Tolentini. Un crimine avvenuto allo IUAV di Venezia. Treviso: Edimedia Libri, 2001.

GUIDOLIN, F.; TATANO, V. Durabilità e patrimonio: accessibilità urbana a Venezia. Milano: Mimesis, 2016.

INSULA. Interventi di infrastrutture urbane e viabilità. Disponível em:

https://www.insula.it/index.php/interventi/interventi-infrastrutture-urbane. Acesso em: 27 jan. 2020.

SOPRINTENDENZA PER I BENI ARCHITETTONICI PER IL PAESAGGIO E PER IL PATRIMONIO STORICO ARTISTICO DI VENEZIA E LAGUNA. Il gradino agevolato come soluzione tecnica alternativa. Venezia: Comune di Venezia, 2011.

\section{NOTAS}

' Com relação à utilização de meios mecânicos para superar barreiras arquitetônicas a Soprintendenza per $i$ Beni Architettonici (2011, p. 5) declara que Veneza possuía instaladas sobre diversas pontes da cidade um total de 9 cadeiras elevatórias, um elevador sobre a Ponte Longo e uma "ovovia" na Ponte della Costituzione, projetada por Santiago Calatrava. ii DECRETO MINISTERIALE no 236/1989: Prescrizioni tecniche necessarie a garantire I"accessibilità, I"adattabilità e la visitabilità degli edifici privati e di edilizia residenziale pubblica sovvenzionata e agevolata, ai fini del superamento $e$ dell"eliminazione delle barriere architettoniche. GU. Serie Generale. 145 (89.06.23) 3-80. Art. 7.2 e 12.

DECRETO PRESIDENCIALE 503/1996: Regolamento recante norme per l"eliminazione delle barriere architettoniche negli edifici, spazi e servizi pubblici. GU. Serie Generale. 227 (96.09.27) 3-40. Art. 19 e 20.

iii A lei prevê ainda que soluções alternativas de alto valor técnico podem desencadear atualização ou modificação das prescrições normativas em vigor, desde que devidamente examinadas e aprovadas por uma Comissão Interministerial. 